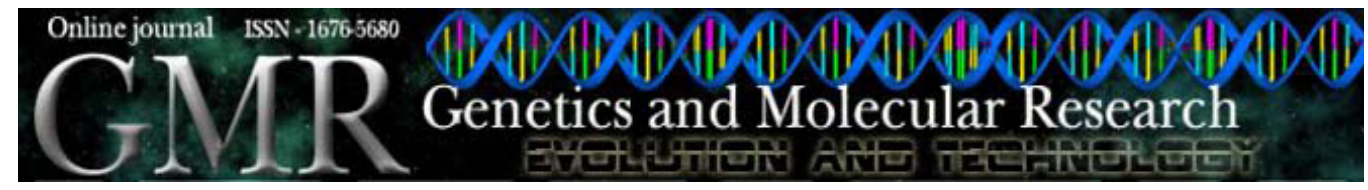

\title{
Cytogenetic and random amplified polymorphic DNA analysis of Leptodactylus species from rural and urban environments (Anura, Amphibia)
}

\author{
M.P. Arruda and E. Morielle-Versute \\ Departamento de Zoologia e Botânica, Instituto de Biociências, \\ Letras e Ciências Exatas, UNESP, São José do Rio Preto, SP, Brasil \\ Corresponding author: E. Morielle-Versute \\ E-mail: morielle@ibilce.unesp.br
}

Genet. Mol. Res. 7 (1): 161-176 (2008)

Received November 15, 2007

Accepted December 27, 2007

Published February 19, 2008

ABSTRACT. Cytogenetic and random amplified polymorphic DNA anal-
yses carried out in the species Leptodactylus podicipinus, L. ocellatus, $L$.
labyrinthicus, and L. fuscus from rural and urban habitats of the northwest
region of São Paulo State, Brazil, showed that the karyotypes $(2 \mathrm{n}=22$ ),
constitutive heterochromatin distribution and nucleolus organizer region
(NOR) location did not differ between the populations from the two en-
vironments. The in situ hybridization with an rDNA probe confirmed the
location of the NORs on chromosome 8 revealing an in tandem duplication
of that region in one of the chromosomes of $L$. fuscus. DAPI showed that
part of the C-band-positive heterochromatin is rich in AT, including that in
the proximity the NORs in $L$. podicipinus and $L$. ocellatus. The molecular
analyses showed that the two populations (urban and rural) of $L$. podicipinus
and $L$. fuscus are similar from a genetic point of view. The urban and rural
populations of species $L$. ocellatus and $L$. labyrinthicus showed differences
in genetic structures, probably due to urbanization which interferes with the
dispersion of those frogs. The marked differences observed between the two
populations of $L$. ocellatus can be representing the cryptic condition of the
species. Unweighted pair-group method of analysis and genetic distance
analysis detected the genetic proximity between $L$. ocellatus and $L$. fuscus. 
The results indicate that there was no reduction in the genetic diversity in the populations from the urban environment; however, the survival of these frogs would not be guaranteed in the case of an increase in human impact especially for populations of L. labyrinthicus and L. ocellatus.

Key words: Cytogenetic; Amphibia; Leptodactylidae; Anthropogenic; Genetic diversity; Random amplified polymorphic DNA

\section{INTRODUCTION}

The disruption of the natural habitat, particularly that caused by human activity, interferes in the environmental dynamics and microclimatic variables such as light intensity, humidity and temperature, and consequently alters the distribution of plants and animals. Some animal groups are less tolerant and are negatively affected by these alterations. Among these, due to their particular morphophysiological characteristics, are the amphibians which have undergone a decrease in numbers in recent decades (Kiesecker et al., 2001; Pounds et al., 2006). This diminution has been attributed to several factors that affect their natural communities such as the destruction and fragmentation of habitats, anthropogenic impacts, climatic change, ozone layer destruction, water pollution, and the introduction of predators (Alexander and Eischeid, 2001; Marsh, 2001; Stuart et al., 2004; Hayes et al., 2006).

The high degree of permeability of the skin of amphibians facilitates the absorption of many environmental substances, making them more sensitive to the contamination of aquatic environments than other vertebrates (Schuytema and Nebeker, 1998). Reductions in population are correlated with the affinity of individuals with their habitat, and the magnitude of population fluctuation indicates the variability, the population dynamics and the risk of the extinction of species (Williams and Hero, 1998).

A means of evaluating the favorable or unfavorable effect of the environment on these organisms is through cytogenetic and molecular analyses, which can supply helpful information in the study of the genetic diversity of species.

Chromosome evolution occurs in parallel with morphological changes; therefore, karyotype analysis provides direct evidence of inter- and intraspecific genetic variability. In Amphibia, some of chromosomal polymorphisms observed have been attributed to the different environments occupied by the populations, which have also been responsible for behavioral, morphological and reproductive alterations (Ruiz et al., 1982; Sessions and Kezer, 1991; Kaiser et al., 1996). Nevertheless, several alterations that arise in the genome of an organism may produce no alteration in karyotype morphology (Ruiz et al., 1982). In such cases, molecular studies are useful. The identification of molecular markers based on DNA analysis has provided a detailed knowledge of the genome of organisms and has constituted important tools for population studies. The most important techniques for identifying molecular markers are restriction fragment length polymorphism, simple sequence repeat and random amplified polymorphic DNA (RAPD).

The RAPD technique detects randomly amplified polymorphic DNA fragments in polymerase chain reaction (PCR) with a single arbitrary primer with 8-10 bp (Williams et al., 1990). The number of fragments amplified and the degree of polymorphism in eukaryotic species depend on the nucleotide sequence, the secondary structure and the number of primers used for each RAPD. 
These features of RAPD make it possible to detect DNA polymorphism in the absence of specific nucleotide sequence information. Thus, the RAPD-PCR method has been used successfully to detect genetic variation within and among related species and populations of different organisms (Zeisset and Beebee, 2003; Li et al., 2006; Dranitsina et al., 2006; Telles et al., 2006).

Recently, some studies in Amphibia have combined cytogenetic and molecular analysis, supplying wider information about the organism studied (Odierna et al., 2004; Silva et al., 2004, 2006).

In addition to environmental alteration and fragmentation being related directly to the decline of amphibian populations, it can also contribute to inductive mutation events, particularly when associated with other factors such as ultraviolet radiation and the increase in pollution (Middleton et al., 2001). The studies described in the literature with genetic analysis in amphibian populations from urban environments are not representative (Hitchings and Beebee, 1997, 1998; Makeeva et al., 2006).

The present study analyzed the genetic variability of four amphibian species that occur in a rural habitat and a urban habitat with anthropogenic activities, by conventional cytogenetics, C-banding and Ag-nucleolus organizer region (NOR) staining, fluorescent in situ hybridization (FISH) with ribosomal DNA probes, 4,6-diamidino-2-phenylindole (DAPI) staining, and molecular analysis with RAPD markers.

\section{MATERIAL AND METHODS}

\section{Population samples}

Fifty-eight adult specimens of Leptodactylus (L. podicipinus, L. labyrinthicus, L. ocellatus, and L. fuscus) were captured in the period between September 2002 and March 2003, in two localities of the northwest region of São Paulo State (Brazil). One site was in rural area of Nova Ita-

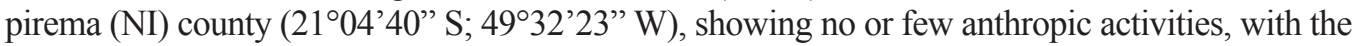
following characteristics: temporary and permanent water areas, marshes, dams, small fragments of semideciduous forests, with overspill formed by pastures. The second site was in the urban and

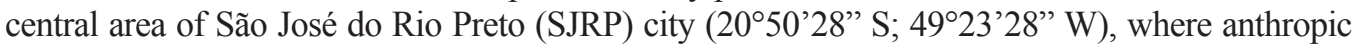
activities are evident: urban watercourse, the Canela Stream, affluent of Preto River, receiving untreated pollutant mixture (domestic sewage not treated plus commercial and industrial residues, as well as deposits of garbage and debris). The area of collection is delimited by two trails running beside an avenue (José Munia Avenue) and characterized by the absence of riparian forest, presence of stagnant water, and flat margins with strong erosion. Despite the proximity between the areas (30 $\mathrm{km}$ ), the populations were considered distinct according to Smith and Green (2005).

\section{Cytogenetic analysis}

In the karyological analysis, two specimens of each habitat from four leptodactylid species

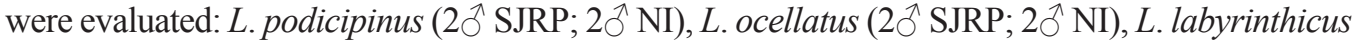

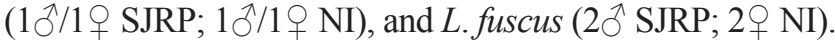

Cell suspensions were obtained directly from bone marrow and liver according to methods of Baldissera Jr. et al. (1993) with modifications. Each specimen was previously treated with $0.01 \%$ colchicine solution at a concentration of $0.1 \mathrm{~mL} / 10 \mathrm{~g}$ body weight and sacrificed $14 \mathrm{~h}$ later after anesthesia with benzocaine. Freshly prepared slides were analyzed after both conventional staining 
(5\% Giemsa at $\mathrm{pH} 7.0)$ and the following banding methods: C-banding (Sumner, 1972) and AgNOR staining (Howell and Black, 1980). FISH, using as probe a recombinant plasmid (HM123) containing a fragment of Xenopus laevis rDNA, biotin-labeled by nick-translation reaction (Gibco), was applied to localize ribosomal genes according to Viegas-Péquignot (1992). Chromosomes were counterstained with propidium iodide and DAPI. Because DAPI fluorochrome has a higher affinity for AT-rich DNA sequences, it was used in the indirect determination of the AT content in the chromosomes of four species.

The slides with the different staining were analyzed in a light microscope fitted with an image analyzer, Axioskop 2 - Zeiss. The best metaphases were selected and photographed for documentation, using the Axio Vision program. FISH slides were analyzed with a fluorescence microscope, and the best images were photographed with Kodak Ultra 400 ASA film, and the images converted into photographs. The chromosomes were classified according to Green and Sessions (1991).

\section{Random amplified polymorphic DNA analysis}

Twelve specimens from each species were evaluated by the RAPD procedure: $L$. podicipinus

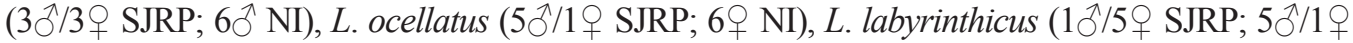
$\mathrm{NI}$ ), and L. fuscus ( $\left.6 \bigcirc^{\lambda} \mathrm{SJRP} ; 6{ }^{\lambda} \mathrm{NI}\right)$. Total genomic DNA was isolated from muscle tissues preserved in 100\% ethanol, according to Sambrook et al. (1989). The specimens analyzed were deposited in the Amphibia Collection of São Paulo State University (UNESP) at São José do Rio Preto, Brazil.

A set of 7 random decanucleotide primers that produced accurate bands was used in the detection of polymorphism among populations: sequence 5' to 3': P1: GGA ACG GGG T; P2: CAG CAC CCA C; P3: GTT GCG ATC C; P4: ACA CCG GAA C; P5: GAC TGC CTC T; P6: AGC AGC GCA C; P7: AGA CGA TGG G (Invitrogen do Brasil). Amplification conditions were according to Williams et al. (1990). The RAPD products were resolved by vertical electrophoresis on $8 \%$ polyacrylamide gels, run with $1 \mathrm{X}$ TBE buffer (trizma base, boric acid, 0.5 M EDTA, pH 8.0) and subsequently stained with silver nitrate.

RAPD-PCR technical limitations were resolved following a strict protocol with standardized conditions, repeating the amplification reactions two or more times.

\section{Data analysis}

RAPD patterns of specimens were determined by direct comparison of the amplified DNA electrophoresis profiles. Fragments were scored as 1 if present or 0 if absent, based on a molecular size standard marker, and the data obtained were analyzed as binary variables. Each band was considered to be an allele of a locus. The size of each band amplified in the gel was estimated in $\mathrm{bp}$, with LABIMAGE 2.7.1 software from the position of a molecular weight marker of pre-established size. The number and frequencies of polymorphic loci and unbiased genetic distances were estimated according to Nei (1978) using POPGENE 1.31 software (Yeh et al., 1999). Analysis of molecular variance (AMOVA) was utilized to verify the variability between and within the populations, with differentiation of significance being tested with 1000 permutations, and Wright's fixation index $\left(\mathrm{F}_{\mathrm{st}}\right)$ was used to estimate the levels of genetic structure in the populations; these analyses were realized with the ARLEQUIN 3.1 software (Excoffier et al., 2005). Clustering was performed by the unweighted pair-group method of analysis (UPGMA) with statistical support obtained by bootstrapping with 100 interactions (PAUP, version 4.0; Swofford, 2002). 


\section{RESULTS}

\section{Cytogenetic analysis}

\section{Leptodactylus podicipinus}

Both specimens of L. podicipinus exhibited a karyotype composed of 22 chromosomes $(2 \mathrm{n}=22)$ represented by three pairs of metacentric $(1,5$ and 6$)$, two pairs of submetacentric ( 2 and 8), two pairs of subtelocentric ( 3 and 4 ), and four pairs of telocentric $(7,9,10$, and 11) chromosomes. There was no detectable difference between the karyotypes of specimens in the two environments analyzed. The NORs detected by AgNOR staining and in situ hybridization were located in the secondary constriction on the long arm of chromosome 8 . A heteromorphism was observed in the secondary constriction size and NORs between the homologous chromosomes (Figure 1A and B); however, no significant differences were observed in the fluorescent signal in FISH experiments with the ribosomal DNA probe (Figure 2A). C-banding revealed small amounts of constitutive heterochromatin in centromeric and telomeric regions in several chromosomes. A large heterochromatic block that extended from the centromeric region to the secondary constriction was observed on chromosome 8 (Figure 1C). This region was positive with DAPI, as well as some centromeric regions (Figure 2B).

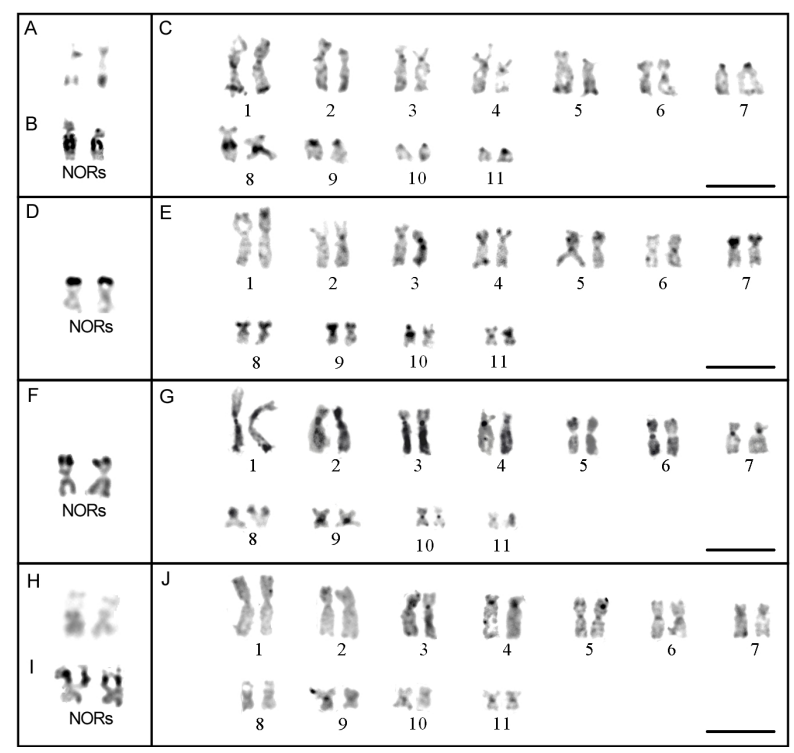

Figure 1. Karyotypes of Leptodactylus species. A. and B. Chromosome 8 in L. podicipinus showing size heteromorphism of the secondary constriction and nucleolus organizer regions (NORs) located in the proximal region of the long arm. C. C-banding in L. podicipinus. D. NORs on chromosome 8 of L. ocellatus located at the termini of the short arm. E. C-banding in L. ocellatus. F. NORs on chromosome 8 of L. labyrinthicus located the termini of the short arm. G. C-banding in L. labyrinthicus. H. and I. Chromosome 8 in L. fuscus showing size heteromorphism of the secondary constriction and NORs located in the median-terminal region of the short arm. J. C-banding in L. fuscus. Bar $=10 \mu \mathrm{m}$. 

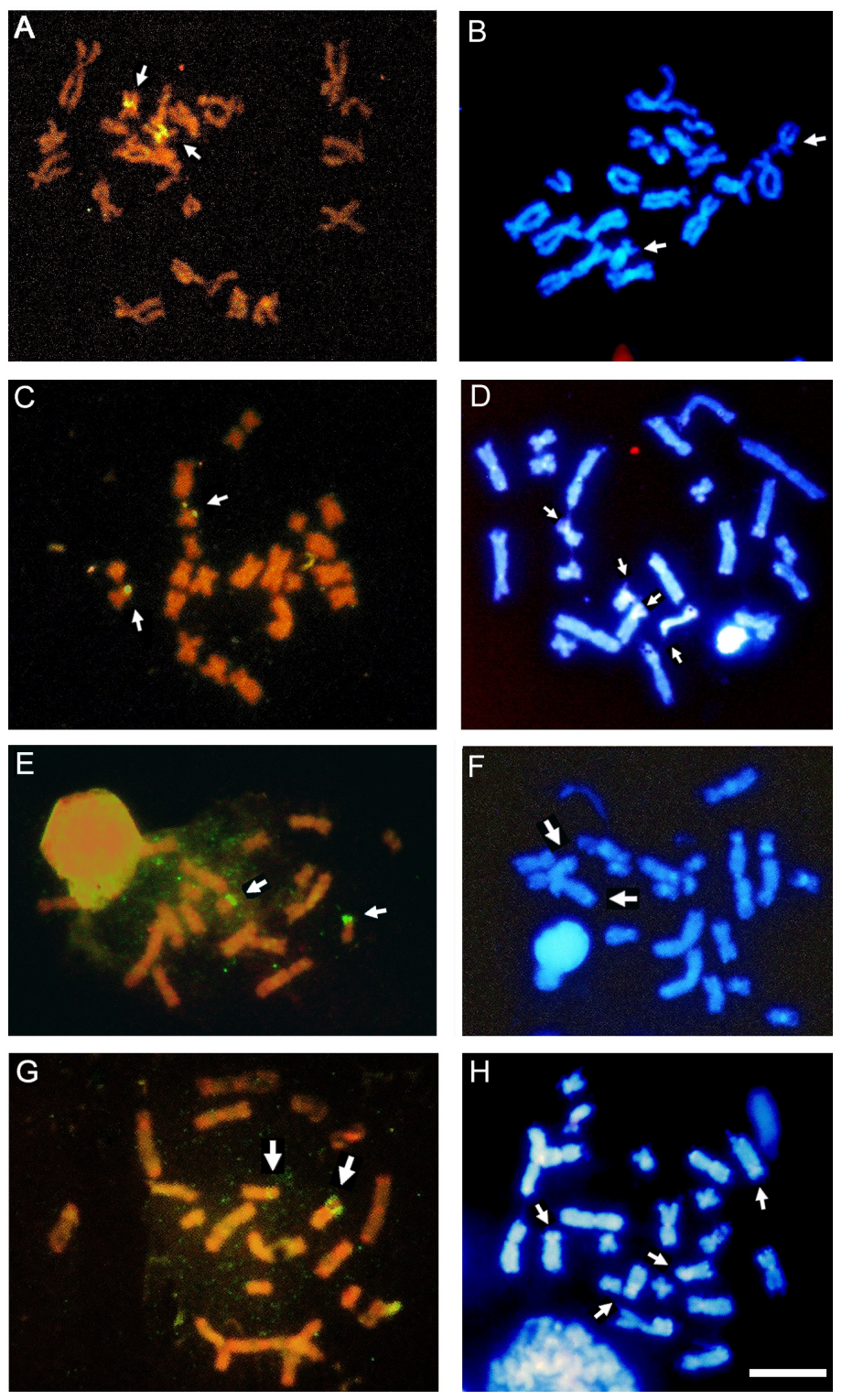

Figure 2. A. and B. Metaphases of Leptodactylus podicipinus with FISH (A) and DAPI staining (B) evincing location of rDNA genes (arrows) and increased fluorescence in secondary constriction of chromosome 8 (arrows). C. and D. Metaphases of L. ocellatus with FISH (C) and DAPI staining (D) evincing location of rDNA genes (arrows) and some heterochromatic regions DAPI ${ }^{+}$(short arms on chromosomes 7 and 8 - arrows). E. and F. Metaphases of L. labyrinthicus with FISH (E) and DAPI staining (F) evincing location of rDNA genes (arrows) and a fluorescent interstitial band on chromosome 2 long arm (arrows). G. and H. Metaphases of L. fuscus with FISH (G) and DAPI staining (H) evincing location of rDNA genes (arrows) and an in tandem duplication in one of the homologs (arrows), and fluorescence in centromeric and telomeric regions and short arm of chromosomes 4 and 7 (arrows). Bar $=10 \mu \mathrm{m}$. 


\section{Leptodactylus ocellatus}

The two populations analyzed exhibited 22 biarmed chromosomes $(2 \mathrm{n}=22)$. The karyotype is composed especially of metacentric and submetacentric chromosomes represented by seven pairs of metacentric (1, 5, 6, and 8 to 11$)$, three pairs of submetacentric (2,3 and 7$)$ and one pair of subtelocentric chromosomes (4). The site of the NORs was found to be on the short arm of chromosome 8 (Figure 1D). In situ hybridization confirmed the NORs position (Figure 2C). Constitutive heterochromatin was found in the centromeric and telomeric regions of chromosomes. An interstitial band was observed on the long arm of chromosome 1 and on short arm of chromosome 5 . The short arm of chromosomes 4, 7, 8, and 9 was completely stained (Figure 1E). The DAPI-positive condition of the heterochromatic blocks was variable, with fluorescence on the short arms of chromosomes 7 and 8 (Figure 2D).

\section{Leptodactylus labyrinthicus}

The karyotypes of the specimens analyzed were similar, showing 22 biarmed chromosomes $(2 \mathrm{n}=22)$ with a prevalence of metacentrics (pairs $1,5,6$, and 8 to 11$)$, two pairs of submetacentrics (2 and 7) and two pairs of subtelocentrics ( 3 and 4). The NORs were observed in the terminal regions of the short arm on chromosome 8, a position confirmed by FISH (Figures $1 \mathrm{~F}$ and $2 \mathrm{E}$ ). The heterochromatin was invariable between the two populations and observed in the centromeric and pericentromeric regions (Figure 1G). Some heterochromatic regions were DAPI-positive, as well as the interstitial region on the long arm of chromosome 2 (Figure 2F).

\section{Leptodactylus fuscus}

The specimens analyzed showed the same karyotypic features, with 22 biarmed chromosomes $(2 \mathrm{n}=22)$. The karyotype was similar to L. ocellatus with seven pairs of metacentric $(1,5,6$, and 8 to 11$)$, three pairs of submetacentric (2, 3 and 7$)$ and one pair of subtelocentric (4). The chromosome pair 8 had a secondary constriction on the median-terminal regions of the short arm, where the NORs were observed. A size heteromorphism was observed in the secondary constriction among homologous chromosomes (Figure 1H and I), and the FISH experiments showed a variation in signal intensity between these chromosomes (Figure 2G). A small amount of constitutive heterochromatin was detected in the centromeric regions, in the interstitial regions of the short arm of chromosome 5 and close to the secondary constriction on pair 8 (Figure 1J), where no staining occurred with DAPI. The centromeric and telomeric regions and the short arm of chromosomes 4 and 7 were stained by DAPI (Figure $2 \mathrm{H}$ ).

\section{Random amplified polymorphic DNA}

\section{Banding polymorphism patterns}

Using RAPD-PCR to analyze intra- and interspecific genomic polymorphism in Amphibia, it was possible to obtain a significantly greater number of amplified fragments. The 7 primers examined produced a total of 267 scorable bands (Table 1). The numbers of fragments varied for primers where 17 to 55 RAPD fragments with a length of 100 to $700 \mathrm{bp}$ were de- 
tected. The number of bands varied in each population and species. L. ocellatus and L. fuscus were the species that produced the greatest number of bands. The number of polymorphic bands and the relative frequencies also varied within and between species and between the populations. The DNA polymorphism observed consisted not only of the presence or absence of fragments with a particular length in the RAPD patterns, but also of a change in the intensity of amplification of fragments with the same length.

Table 1. Primers, number of polymorphic bands, polymorphism frequencies, and values of the genetic diversity observed in the different populations and species: Leptodactylus podicipinus, L. ocellatus, L. labyrinthicus, L. fuscus.

\begin{tabular}{|c|c|c|c|c|c|c|c|c|c|}
\hline \multirow[t]{2}{*}{ Primer } & \multicolumn{2}{|c|}{ L. podicipinus } & \multicolumn{2}{|c|}{ L. ocellatus } & \multicolumn{2}{|c|}{ L. labyrinthicus } & \multicolumn{2}{|c|}{ L. fuscus } & \multirow[t]{2}{*}{ Tota } \\
\hline & SJRP & NI & SJRP & NI & SJRP & NI & SJRP & NI & \\
\hline 1 & $2 / 2$ & $0 / 0$ & $9 / 12$ & $12 / 12$ & $13 / 13$ & $11 / 11$ & $5 / 6$ & $7 / 7$ & 23 \\
\hline 2 & $9 / 20$ & $13 / 21$ & $12 / 18$ & $13 / 18$ & $14 / 24$ & $4 / 16$ & $22 / 25$ & $21 / 22$ & 45 \\
\hline 3 & $10 / 11$ & $3 / 3$ & $14 / 14$ & $17 / 18$ & $22 / 26$ & $16 / 16$ & $25 / 25$ & $23 / 23$ & 39 \\
\hline 4 & $0 / 0$ & $0 / 0$ & $2 / 2$ & $3 / 3$ & $5 / 6$ & $9 / 9$ & $2 / 2$ & $5 / 5$ & 17 \\
\hline 5 & $17 / 17$ & $14 / 17$ & $10 / 22$ & $23 / 26$ & $7 / 16$ & $10 / 12$ & $19 / 23$ & $20 / 22$ & 41 \\
\hline 6 & $29 / 30$ & $11 / 24$ & $5 / 21$ & $23 / 23$ & $13 / 27$ & $13 / 26$ & $15 / 24$ & $19 / 26$ & 47 \\
\hline 7 & $31 / 34$ & $13 / 23$ & $9 / 19$ & $19 / 23$ & $12 / 19$ & $15 / 20$ & $20 / 23$ & $25 / 25$ & 55 \\
\hline Total & \multicolumn{2}{|c|}{120} & \multicolumn{2}{|c|}{152} & \multicolumn{2}{|c|}{146} & \multicolumn{2}{|c|}{151} & 267 \\
\hline $\begin{array}{l}\text { Polymorphism } \\
\text { frequency }(\%)\end{array}$ & $81.6 \%$ & $45.0 \%$ & $40.1 \%$ & $72.3 \%$ & $59.7 \%$ & $54.2 \%$ & $72.9 \%$ & $81.1 \%$ & \\
\hline Population & 0.27 & 0.18 & 0.14 & 0.26 & 0.21 & 0.19 & 0.27 & 0.30 & \\
\hline Species & \multicolumn{2}{|c|}{0.25} & \multicolumn{2}{|c|}{0.35} & \multicolumn{2}{|c|}{0.25} & \multicolumn{2}{|c|}{0.32} & \\
\hline
\end{tabular}

Data are reported as number of polymorphic bands/total bands. SJRP = São José do Rio Preto (urban environment), $\mathrm{NI}=$ Nova Itapirema (rural environment).

The highest polymorphism frequencies were observed in the urban population of L. podicipinus $(81.6 \%)$ and L. labyrinthicus $(59.7 \%)$ and in rural population of L. ocellatus (72.3\%) and L. fuscus $(81.1 \%)$.

\section{Gene diversity and genetic distance}

The Nei gene diversity index for the two populations in the four species was not greater than 0.30 (Table 1), which was observed in L. fuscus specimens from NI. However, the highest values were not necessarily exhibited by specimens from the rural habitat. The lowest diversity indexes were exhibited by L. podicipinus from NI and L. ocellatus from SJRP $(0.18$ and 0.14 , respectively). L. labyrinthicus and L. fuscus showed similar values of genetic variation between the populations of the two environments. For the species, the highest value of genetic diversity was detected in L. ocellatus ( 0.35$)$ and the lowest to L. podicipinus $(0.25), L$. labyrinthicus (0.25) and L. fuscus (0.32). The higher values of genetic diversity displayed by L. ocellatus reinforce the differences observed between the values of populations.

Estimates of Nei's unbiased genetic distances between individuals of the populations (rural and urban) and species are shown in Tables 2 and 3. The greatest genetic distances were observed for the individuals from the populations of L. ocellatus $(0.21)$ and L. labyrinthicus (0.06), whereas the lowest distance values were obtained in the populations of L. podicipinus (0.04) and L. fuscus (0.04). Among species, the greatest distance was observed between L. labyrinthicus and L. podicipinus (0.19) and the least between L. fuscus and L. ocellatus (0.10). 
Table 2. Nei's genetic distance (1978) among the eight populations, Leptodactylus podicipinus, L. ocellatus, L. labyrinthicus, and L.fuscus, after the evaluation of the 267 loci.

\begin{tabular}{|c|c|c|c|c|c|c|c|c|}
\hline \multirow[t]{2}{*}{ Population } & \multicolumn{2}{|c|}{ L. podicipinus } & \multicolumn{2}{|c|}{ L. ocellatus } & \multicolumn{2}{|c|}{ L. labyrinthicus } & \multicolumn{2}{|c|}{ L. fuscus } \\
\hline & SJRP & NI & SJRP & NI & SJRP & NI & SJRP & NI \\
\hline L. podicipinus (SJRP) & $* * * *$ & & & & & & & \\
\hline L. podicipinus $(\mathrm{NI})$ & 0.04 & $* * * *$ & & & & & & \\
\hline L. ocellatus (SJRP) & 0.26 & 0.29 & $* * * *$ & & & & & \\
\hline L. ocellatus $(\mathrm{NI})$ & 0.18 & 0.21 & 0.21 & $* * * *$ & & & & \\
\hline L. labyrinthicus (SJRP) & 0.25 & 0.30 & 0.31 & 0.23 & $* * * *$ & & & \\
\hline L. labyrinthicus (NI) & 0.20 & 0.24 & 0.31 & 0.21 & 0.06 & $* * * *$ & & \\
\hline L. fuscus (SJRP) & 0.17 & 0.21 & 0.24 & 0.18 & 0.24 & 0.19 & $* * * *$ & \\
\hline L. fuscus (NI) & 0.15 & 0.19 & 0.22 & 0.14 & 0.23 & 0.17 & 0.04 & $* * * *$ \\
\hline
\end{tabular}

$\mathrm{SJRP}=$ São José do Rio Preto (urban environment), NI = Nova Itapirema (rural environment).

Table 3. Genetic distance according to Nei (1978) generated by the analysis of the 267 fragments in the four species.

\begin{tabular}{lccc}
\hline Species & L. podicipinus & L. ocellatus & L. labyrinthicus \\
\hline L. podicipinus & $* * * *$ & & \\
L. ocellatus & 0.13 & $* * * *$ & $* * * *$ \\
L. labyrinthicus & 0.19 & 0.16 & 0.16 \\
L.fuscus & 0.13 & 0.10 & $* * * *$ \\
\hline
\end{tabular}

The UPGMA dendrogram showed the same topology in POPGENE and PAUP analyses, showing a bootstrap support (100 replications) for the groups observed of 97 and 86\% (Figure 3). In the figure it can be observed that L. labyrinthicus is more basal and that the three other species are clustered. Furthermore, L. ocellatus was found to be closer to L. fuscus than to L. podicipinus.

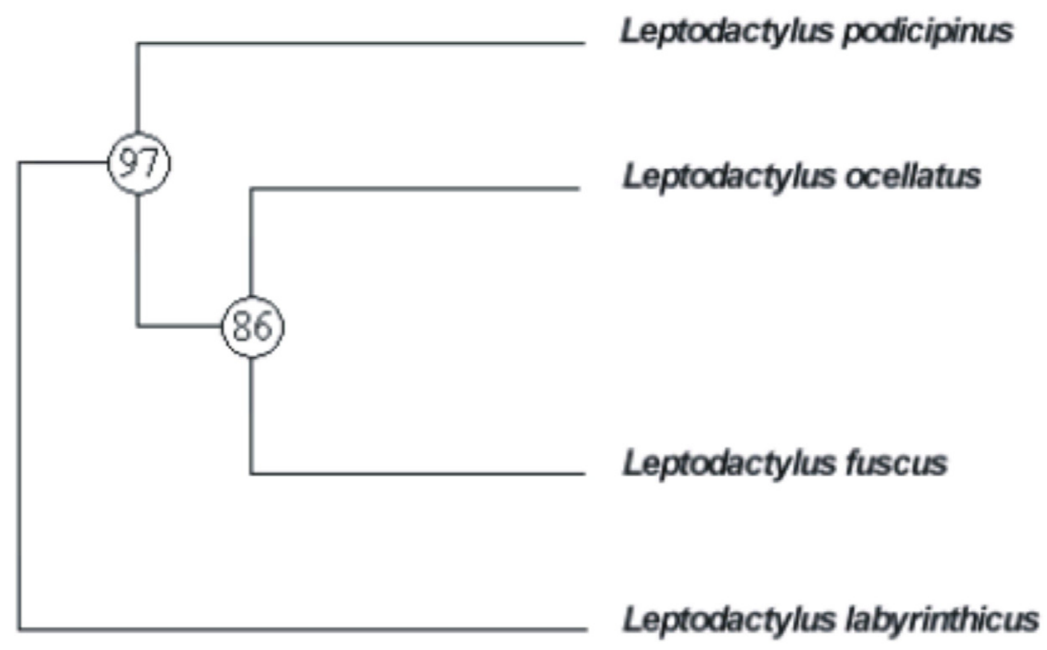

Figure 3. Dendogram of genetic similarity for the four species based on the UPGMA method. 


\section{Analysis of molecular variance and fixation index}

Hierarchical AMOVA was used to investigate the differentiation between the two sampling localities for each species. The results presented in Table 4 show that the lowest values of variations in the interpopulational component occurred between the populations of $L$. fuscus (6.57\%) and the highest between L. ocellatus (53.45\%) and L. labyrinthicus populations (17.84\%). The $\mathrm{F}_{\mathrm{st}}$ value analysis in L. ocellatus $\left(\mathrm{F}_{\mathrm{st}}=0.534\right)$ and L. labyrinthicus $\left(\mathrm{F}_{\mathrm{st}}=0.178\right)$ reinforced the differences observed in the populations and was confirmed by the $\mathrm{P}$ value $(\mathrm{P}<0.01)$.

\begin{tabular}{|c|c|c|c|c|c|}
\hline Taxon & $\begin{array}{c}\% \text { among } \\
\text { populations }\end{array}$ & $\begin{array}{l}\% \text { within } \\
\text { populations }\end{array}$ & $\mathrm{F}_{\mathrm{st}}$ & $\mathrm{F}_{\mathrm{st}}($ median$)$ & $P$ value \\
\hline L. podicipinus & $7.47 \%$ & $92.5 \%$ & $\begin{aligned} \mathrm{SJRP} & =0.03 \\
\mathrm{NI} & =0.11\end{aligned}$ & 0.074 & 0.090 \\
\hline L. ocellatus & $53.45 \%$ & $46.55 \%$ & $\begin{aligned} \mathrm{SJRP} & =0.55 \\
\mathrm{NI} & =0.51\end{aligned}$ & 0.534 & $0.000^{*}$ \\
\hline L. labyrinthicus & $17.84 \%$ & $82.16 \%$ & $\begin{aligned} \mathrm{SJRP} & =0.17 \\
\mathrm{NI} & =0.18\end{aligned}$ & 0.178 & $0.001 *$ \\
\hline L. fuscus & $6.57 \%$ & $93.43 \%$ & $\begin{aligned} \mathrm{SJRP} & =0.07 \\
\mathrm{NI} & =0.05\end{aligned}$ & 0.065 & 0.017 \\
\hline
\end{tabular}

$\mathrm{SJRP}=$ São José do Rio Preto (urban environment), NI = Nova Itapirema (rural environment). *Statistically significant.

\section{DISCUSSION}

\section{Cytogenetic analysis}

The karyotypes of the four species of leptodactylid analyzed are similar to that described by Denaro (1972), Bianchi et al. (1973), Bogart (1974), Agostinho (1994), Silva et al. (2000), Baldo (2002), and Amaro-Ghilardi et al. (2006) who pointed out the conservatism of the Leptodactylus karyotypes. Despite that no significant difference was observed in morphology, the pattern of C-banding or NOR localization between the specimens from the two environments and the occurrence of chromosomal polymorphisms in different amphibian populations were related, involving especially the diploid number, NORs and constitutive heterochromatin (Ruiz et al., 1981; Silva et al., 1999, 2000; Lourenço et al., 1998, 2003; Medeiros et al., 2003; Rosa et al., 2003).

Silva et al. (2000) determined the location of the constitutive heterochromatin in specimens of the three populations of L. fuscus and four of L. ocellatus in Brazil and demonstrated distinct patterns in distribution of heterochromatin between them. The most variable species was $L$. ocellatus in which three distinct C-banding patterns were noted. Although the authors did not attribute the findings to taxonomically diverse forms, they referred to some differences concerning the external morphology and bioacustics between animals occurring in different geographical localities. 
The specimens of L. ocellatus analyzed in the present study showed similarity with the condition observed by Silva et al. (2000) in individuals of Anaurilândia, MS, which showed interstitial heterochromatin on the short arm of chromosomes 5, 9 and 10, besides telomeric bands. Moreover, the individuals of L. fuscus were more similar to the specimens of Silva et al. (2000) collected in Rio Claro, SP, because they did not have the marked telomeric bands observed in most of the chromosomes of individuals.

The species L. labyrinthicus was also studied by Silva et al. (2000) who detected an interstitial C-band on the long arm of the chromosome 2. In our study, this band was not visualized, but a coincident region that was DAPI-positive was observed. According to Schmid (1978), small variations in the treatment with barium used in C-banding can show or hide regions of constitutive heterochromatin, which probably occurred in this case.

Despite differences in position, the occurrence of a secondary constriction on chromosome 8, carrier of the NORs in species of Leptodactylus was referred to by Baldo (2002) and Amaro-Ghilardi et al. (2006). In the present study, only on chromosome 8 of L. labyrinthicus was the secondary constriction not observed, probably due to differences in the degree of chromosome condensation in preparations. However, the NOR location detected by silver staining and FISH was observed in the terminal position, as was observed by the above authors, possibly at the constriction site.

The heteromorphism in the size of the secondary constriction and NORs observed in $L$. podicipinus and L. fuscus was also detected by Baldo (2002). The differences observed in size of constrictions have been attributed mainly to the variation in the quantity of constitutive heterochromatin that is generally present in these regions, and other factors such as chromosome rearrangements and amplifications of the DNA regions (King, 1980). In the present study, it is possible that in L. podicipinus, the heteromorphism in the size of the secondary constriction and NORs can be attributed mainly to a different degree in condensation between homologs and to differential genetic activity of rDNA segments, since no variation was observed in the intensity of the hybridization signal with the rDNA probe that could indicate the occurrence of duplication or amplification of ribosomal cistrons. However, in L. fuscus, FISH with the ribosomal probe not only confirmed the NOR position in the secondary constriction but also detected an in tandem duplication at the site of the rDNA in individuals from the two populations.

The increased fluorescence exhibited by DAPI in the majority of the centromeric regions of chromosomes in some telomeres and in the proximal region of the long and short arms, respectively, of the chromosome pair bearing the NORs in L. podicipinus and L. ocellatus was coincident with regions that were $\mathrm{C}$-band positive.

DAPI is a fluorescent stain that binds strongly to double-stranded DNA, particularly that with high AT content (Lin et al., 1977). The DAPI-positive fluorescence in regions of heterochromatin in the species analyzed is indicative of the presence of A-T bases in centromeres and telomeres of the chromosomes of the four species. This is contrary to other studies which reported a relative wealth of G-C base pairs in constitutive heterochromatin of centromeric and telomeric regions of chromosomes in species of amphibians (Schmid, 1980; Schmid et al., 1985, 1993; Silva et al., 2006).

Despite this relation between constitutive heterochromatin and DAPI, some C-positive regions did not display increased fluorescence, suggesting that the heterochromatic fractions have heterogeneous contents of G-C and A-T base pairs in the four species.

The association or proximity between heterochromatin and ribosomal cistrons is very common on chromosomes of vertebrates. In Anura, ribosomal DNA is rich in G-C content, 
about 64\%, a value considered high, when compared with other groups of vertebrates (Sinclair and Brown, 1971; Schweizer, 1976; Schmid, 1980; Sumner, 1990). Based on the results of the present study, it can be pointed out that DAPI-positive staining in the proximal region of NORs in L. podicipinus and L. ocellatus is probably due to the proximity of AT-rich heterochromatin.

The absence of variations between the karyotypes of the individuals in all the species from the two different environments enables us to conclude that, in the individuals evaluated, no inference can be drawn about the action of an altered urban environment on the karyotypes of the species in the genus Leptodactylus.

\section{Random amplified polymorphic DNA analysis}

The results observed show that RAPD-PCR is capable of revealing polymorphism in amphibian species. All 7 random decanucleotide primers produced at least one polymorphic fragment.

The wide study carried out by Makeeva et al. (2006), which analyzed the genetic structure in two species of brown frog Rana (Ranidae), using isoenzymatic markers, detected a reduction in diversity and polymorphisms in populations from an urban environment when compared with populations from a rural environment. The authors pointed out that the unfavorable conditions of gene pool in the specimens of urban populations can be due probably to the gene drift accompanied by fragmentation of the urban environments, which causes a reduction in the populations and consequent inbreeding. In the present study, the highest frequencies of polymorphism were not related to rural habitat only. The differences in frequencies of polymorphisms in the populations point to different adaptive strategies (plasticity).

The values of genetic distance and of interpopulational component of the molecular variation were directly correlated for the four species. The values of genetic diversity and the analyses of molecular variation in the small species (snout vent length $<50 \mathrm{~mm}$ ), L. podicipinus and L. fuscus, showed that the two populations of these species are similarly structured, with a low variation in the interpopulational component and a high variation within the populations ( $90 \%$ on average). The $\mathrm{F}_{\mathrm{st}}$, characterized by estimating the genetic differentiation between populations, showed a low value for these two species.

To Telles et al. (2006), who analyzed RAPD markers from 214 individuals of Physalaemus cuvieri sampled from 18 populations of different size ( 7 to 23 individuals) from Goiás State (Brazil), the values were observed to vary in the interpopulational component and $\mathrm{F}_{\text {st }}$ ( $10 \%$ and 0.101 , respectively), which were a little higher than those in the present study for the small species, and can be attributed to the abundance of individuals of populations that buffer the effect of the stochastic process combined with a low and restricted gene flow. This can be just occurring with L. podicipinus and L. fuscus populations. The authors pointed out yet that a recent human occupation and habitat fragmentation may also explain part of the genetic variation observed in the interpopulational component.

Apparently, the species L. podicipinus and L. fuscus are equally adapted to the two environments studied. The species L. fuscus has a wide geographical range (the greatest of the four species) and is considered an invader species (very generalist) with a moderate dispersion potential (Wynn and Heyer, 2001). The data obtained in the present study corroborate this hypothesis. 
The large species (snout vent length $>100 \mathrm{~mm}$ ), L. ocellatus and L. labyrinthicus, exhibited a high variation in the interpopulational component $(53.45 \%$ and $17.84 \%$, respectively) as well as the highest genetic distance between the populations in relation to the small species. The fixation index $\left(\mathrm{F}_{\text {st }}=0.534\right.$ in L. ocellatus and $\mathrm{F}_{\text {st }}=0.178$ in L. labyrinthicus $)$ and the values of genetic diversity show that there are differences in genetic structure between the two populations, especially for L. ocellatus.

Although there are no geographical barriers limiting the dispersion of these frogs analyzed, Johnston and Frid (2002) found that in salamanders, dispersion was reduced due to human activities such as the presence of roads and urbanization. It is possible that these had been occurring with urban populations of L. ocellatus and L. labyrinthicus.

The species of the ocellatus group include representatives with very similar morphology, which complicates the taxonomic characterization of the species (Dela Riva and Maldonado, 1999; Ribeiro et al., 2005). On the basis of this fact and of the results obtained, it cannot be ruled out that the marked differences observed in the two populations of L. ocellatus analyzed are possibly a consequence of these animals belonging to cryptic species.

In the small frogs (L. podicipinus and L. fuscus), the fragmentation of the urban environment seems to have been insufficient to differentiate the populations studied, whereas in

L. labyrinthicus and L. ocellatus this disruption of the habitat influenced the structuring of the populations, with possible adaptations to the environment. Despite of the differences between the populations of the four species, the fragmentation did not apparently affect their viability. The barriers in the city seem to alter only the dispersion of the large frogs.

The present study suggests that amphibian populations respond to environmental variations in varying ways. The results also suggest that there was no diminution in the adaptive value of the four species of the urban environment. Probably, these species of the genus Leptodactylus are, from a genetic point of view, adapted to anthropic activity. Studies of spatial distribution (Izecksohn and Carvalho-e-Silva, 2001; Ávila and Ferreira, 2004; Grandinetti and Jacobi, 2005) have already indicated the persistence of these species in urban environments. Despite these considerations, the medium- and long-term survival of these frogs, in general under the influence of human activity, is not guaranteed, especially for populations of $L$. labyrinthicus and L. ocellatus.

The taxonomic proximity between the species L. ocellatus (ocellatus group) and $L$. fuscus (fuscus group), evinced in the phenogram (UPGMA) and cytogenetic analysis, was also observed by Bogart (1974) after analyzing karyotypes of the species of Leptodactylus. However, they diverge from other published studies (Miyamoto, 1981; Masxon and Heyer, 1988; Larson and Sá, 1998; Heyer and Muñhoz, 1999), which were based upon behavior, morphology and molecular markers. The discrepancies found between the studies can be related to the utilization of different markers and methods of analyses, as well as to the species chosen, justifying the realization of different studies, utilizing a combination of techniques and a greater number of species.

\section{ACKNOWLEDGMENTS}

The authors are grateful to Dr. Sanae Kasahara for helping with the cytogenetic technical procedures, Dr. Shirlei Maria Recco-Pimentel for providing the probe and Dr. Peter James Harris for suggestions regarding the English of the manuscript. We also thank CAPES 
(Coordenadoria de Aperfeiçoamento de Pessoal de Ensino Superior) for financial support and the researchers of the Chiroptera laboratory.

\section{REFERENCES}

Agostinho CA (1994). Caracterização de populações de rã-pimenta Leptodactylus labyrinthicus (Spix, 1824) e avaliação de seu desempenho em cativeiro. Unpublished Ph.D. thesis, Universidade Federal de São Carlos, São Carlos.

Alexander MA and Eischeid JK (2001). Climate variability in regions of amphibian declines. Conserv. Biol. 15: 930-942.

Amaro-Ghilardi RC, Skuk G, Sá RO, Rodrigues MT, et al. (2006). Karyotypes of eight species of Leptodactylus (Anura, Leptodatylidae) with a description of a new karyotype for the genus. Phyllomedusa 5: 119-133.

Ávila RW and Ferreira VL (2004). Riqueza e densidade de vocalizações de anuros (Amphibia) em uma área urbana de Corumbá, Mato Grosso do Sul, Brasil. Rev. Bras. Zool. 21: 887-892.

Baldissera A Jr, Oliveira PSL and Kasahara S (1993). Cytogenetics of four Brazilian Hyla species (Amphibia-Anura) and description of a case with a supernumerary chromosome. Rev. Bras. Genet. 16: 335-345.

Baldo J (2002). Estudios cromossómicos de las especies argentinas del género Leptodactylus Fitzinger 1826 (Amphibia, Anura). Unpublished Ph.D. thesis, Baldo, JD, Argentina.

Bianchi NO, Bianchi M and Vidal-Rioja L (1973). Heterochromatin late replication and secondary constrictions in the chromosome complement of Leptodactylus ocellatus. J. Gerontol. A. Biol. Sci. Med. Sci. 26: 397-403.

Bogart JP (1974). A Karyosystematic study of frogs in the genus Leptodactylus (Anura: Leptodactylidae). Copeia 3: 728-737.

Dela Riva I and Maldonado M (1999). First record of Leptodactylus ocellatus (Linnaeus, 1758) (Amphibia, Anura, Leptodactykudae) in Bolivia and comments on related species. Graellsia 55: 193-197.

Denaro L (1972). Karyotypes of Leptodactylidae anurans. J. Herpetol. 6: 71-74.

Dranitsina AS, Telegeev GD, Maliuta SS and Bezrukov VF (2006). Genetic diversity in populations of Gentoo penguins (Pygoscelis papua). Tsitol. Genet. 40: 57-62.

Excoffier L, Laval G and Schneider S (2005). Arlequin (version 3.0): An integrated population genetics data analysis. Evolutionary Bioinformatics Online 1: 47-50.

Grandinetti L and Jacobi CM (2005). Distribuição estacional e espacial de uma taxocenose de anuros (Amphibia) em uma área antropizada em Rio Acima - MG. Lundiana 6: 21-28.

Green DM and Sessions SK (2007). Nomenclature of chromosomes. In: Amphibian cytogenetics and evolution (Green DM and Sessions SK, eds.). Academic Press, San Diego,

Hayes TB, Case P, Chui S, Chung D, et al. (2006). Pesticide mixtures, endocrine disruption, and amphibian declines: are we underestimating the impact? Environ. Health Perspect. 114 (Suppl 1): 40-50.

Heyer WR and Muñhoz AM (1999). Validation of Eleutherodactylus crepitans Bokermann, 1965; Notes on the types and type locality of Telatrema heterodactylum Miranda-Ribeiro, 1937; and description of a new species of Eleutherodactylus from Mato Grosso, Brazil (Amphibia: Anura: Leptodactylidae). Proc. Biol. Soc. Wash. 112: 1-18.

Hitchings SP and Beebee TJC (1998). Loss of genetic diversity and fitness in common toad (Bufo bufo) populations isolated by inimical habitat. J. Evol. Biol. 11: 269-283.

Hitchings SP and Beebee TJ (1997). Genetic substructuring as a result of barriers to gene flow in urban Rana temporaria (common frog) populations: implications for biodiversity conservation. Heredity 79 (Pt 2): 117-127.

Howell WM and Black DA (1980). Controlled silver-staining of nucleolus organizer regions with a protective colloidal developer: a 1-step method. Experientia 36: 1014-1015.

Izecksohn E and Carvalho-e-Silva SP de (2001). Anfíbios do município do Rio de Janeiro. UFRJ, Rio de Janeiro, 148.

Johnston B and Frid L (2002). Clearcut logging restricts the movement of terrestrial Pacific giant salamanders (Dicamptodon tenebrosus Good). Can. J. Zool. 80: 2170-2177.

Kaiser H, Mais C, Bolaños F and Steinlein C (1996). Chromosomal investigation of three Costa Rican frogs from the 30-chromosome radiation of Hyla with the description of a unique geographic variation in nucleolus organizer regions. Genetica 98: 95-102.

Kiesecker JM, Blaustein AR and Belden LK (2001). Complex causes of amphibian population declines. Nature 410: 681-684.

King M (1980). C-banding studies on Australian hylid frogs: secondary constriction structure and the concept of euchromatin transformation. Chromosoma 80: 191-217. 
Larson P and Sá RO de (1998). Chondrocranial morphology of Leptodactylus larvae (Leptodactylidae: Leptodactylinae): its utility in phylogenetic reconstruction. J. Morphol. 238: 287-305.

Li L, Zhang J, Zhu JQ, Gu S, et al. (2006). Genetic diversity of nine populations of the black goat (Capra hircus) in Sichuan, PR China. Zoolog. Sci. 23: 229-234.

Lin MS, Comings DE and Alfi OS (1977). Optical studies of the interaction of 4'-6'-diamidino-2-phenylindole with DNA and metaphase chromosomes. Chromosoma 60: 15-25.

Lourenço LB, Recco-Pimentel SM and Cardoso AJ (1998). Polymorphism of the nucleolus organizer regions (NORs) in Physalaemus petersi (Amphibia, Anura, Leptodactylidae) detected by silver staining and fluorescence in situ hybridization. Chromosome Res. 6: 621-628.

Lourenço LB, Garcia PCA and Recco-Pimentel SM (2003). Cytogenetics of a new species of Paratelmatobius cardosoi group (Anura: Leptodactylidae), with the description of an apparent case of pericentric inversion. Amphibia-Reptilia 24: 47-55.

Makeeva VM, Belokon' MM, Maliuchenko OP and Leont'eva OA (2006). Evaluation of the state of the gene pool of natural populations of vertebrate animals inhabiting the fragmented landscape of Moscow and Moscow district (with special reference to brown frogs). Genetika 42: 628-642.

Marsh DM (2001). Fluctuations in amphibian populations: a meta-analysis. Biol. Conserv. 101: 327-335.

Masxon LR and Heyer WR (1988). Molecular systematics of the frog genus Leptodactylus (Amphibia: Leptodactylidae). Fieldiana Zool. 41: 1-13.

Medeiros LR, Rossa-Feres DC and Recco-Pimentel SM (2003). Chromosomal differentiation of Hyla nana and Hyla sanborni (Anura, Hylidae) with a description of NOR polymorphism in H. nana. J. Hered. 94: 149-154.

Middleton EM, Herman JR, Celarier EA, Wilkinson JW, et al. (1981). Evaluating ultraviolet radiation exposure with satellite data at sites of amphibian declines in Central and South America. Conserv. Biol. 15: 914-928.

Miyamoto MM (1981). Congruence among character sets in phylogenetic studies of the frog genus Leptodactylus. Syst. Zool. 30: 281-290

Nei M (1978). Estimation of average heterozygosity and genetic distance from a small number of individuals. Genetics 89: $583-590$

Odierna G, Aprea G, Capriglion T, Castellano S, et al. (2004). Evidence for chromosome and Pst I satellite DNA family evolutionary stasis in the Bufo viridis group (Amphibia, Anura). Chromosome Res. 12: 671-681.

Pounds JA, Bustamante MR, Coloma LA, Consuegra JA, et al. (2006). Widespread amphibian extinctions from epidemic disease driven by global warming. Nature 439: 161-167.

Ribeiro RS, Egito GTBT and Haddad FB (2005). Chave de identificação: anfíbios anuros da vertente de Jundiaí da Serra do Japi, Estado de São Paulo. Biota Neotrop. 5: 235-247.

Rosa C, Aguiar O Jr, Giaretta AA and Recco-Pimentel SM (2003). Karyotypic variation in the genus megaelosia (Anura, Hylodinae) with the first description of a B-chromosome in a leptodactylid frog. Copeia 1: 166-174.

Ruiz IR, Soma M and Becak W (1981). Nucleolar organizer regions and constitutive heterochromatin in polyploid species of the genus Odontophrynus (Amphibia, Anura). Cytogenet. Cell Genet. 29: 84-98.

Ruiz IR, Ceis JM and Becak W (1982). Chromosomal evolution in allopatric populations of the Odontophrynus occidentalis group (Amphibia, Anura) from western Argentina. Cytogenet. Cell Genet. 33: 303-311.

Sambrook J, Fritsch EF and Maniatis T (1989). Molecular cloning - a laboratory manual. Cold Spring Harbor Laboratory Press, New York.

Schmid M (1978). Chromosome banding in Amphibia. I. Constitutive heterochromatin and nucleolus organizer regions in Bufo and Hyla. Chromosoma 66: 361-388.

Schmid M (1980). Chromosome banding in amphibia. IV. Differentiation of GC- and AT-rich chromosome regions in Anura. Chromosoma 77: 83-103.

Schmid M (1983). Chromosome banding in amphibia - VII analysis of the structure and variability of NORs in Anura. Chromosoma 87: 327-344.

Schmid M, Haaf T and Schempp W (1985). Chromosome banding in Amphibia. IX. The polyploid karyotypes of Odontophrynus americanus and Ceratophrys ornata (Anura, Leptodactylidae). Chromosoma 91: 172-184.

Schmid M, Steinlein C, Feichtinger W and Poot M (1993). Chromosome banding in Amphibia. XVIII. Karyotype evolution and genomic size variation in Pleurodema (Anura, Leptodactylidae). Cytogenet. Cell Genet. 62: 42-48.

Schuytema GS and Nebeker AV (1998). Comparative toxicity of diuron on survival and growth of Pacific treefrog, bullfrog, red-legged frog, and African clawed frog embryos and tadpoles. Arch. Environ. Contam. Toxicol. 34: 370-376.

Schweizer D (1976). Reverse fluorescent chromosome banding with chromomycin and DAPI. Chromosoma 58: 307-324.

Sessions SK and Kezer J (1991). Evolutionary cytogenetics of bolitoglossine salamanders (family Plethodontidae). In: Green DMIn: Amphibian cytogenetics and evolution (Green DM and Sessions SK, eds.). Academic Press, San 
Diego, 89-130.

Silva APZ, Garcia PCA, Martins VG, Bacci M, et al. (2004). Chromosomal and molecular analyses of Leptodactylus gracilis, L. gracilis dellatini, and L. plaumanni (Anura, Leptodactylidae): Taxonomic Implications. AmphibiaReptilia 25: 185-196.

Silva AP, Haddad CF and Kasahara S (1999). Nucleolus organizer regions in Physalaemus cuvievi (Anura, Leptodactylidae), with evidence of a unique case of Ag-NOR variability. Hereditas 131: 135-141.

Silva AP, Haddad CF and Kasahara S (2000). Chromosomal studies on five species of the genus Leptodactylus Fitzinger, 1826 (Amphibia, Anura) using differential staining. Cytobios 103: 25-38.

Silva AP, Haddad CF, Galassi GG and Kasahara S (2006). Multiple nucleolus organizer regions in Leptodactylus mystacinus (Amphibia, Anura) and comments on its systematic position in the L. fuscus group based on cytogenetic and molecular analyses. Genetica 127: 35-44.

Sinclair JH and Brown DD (1971). Retention of common nucleotide sequences in the ribosomal deoxyribonucleic acid of eukaryotes and some of their physical characteristics. Biochemistry 10: 2761-2769.

Smith MA and Green DM (2005). Dispersal and the metapopulation paradigm in amphibian ecology and conservation: are all amphibian populations metapopulations? Ecography 28: 110-128.

Stuart SN, Chanson JS, Cox NA, Young BE, et al. (2004). Status and trends of amphibian declines and extinctions worldwide. Science 306: 1783-1786.

Sumner AT (1990). Chromosome banding. Unwin Hyman, London, 434.

Sumner AT (1972). A simple technique for demonstrating centromeric heterochromatin. Exp. Cell Res. 75: 304-306.

Swofford DL (2002). PAUP*. Phylogenetic Analysis Using Parsimony (*and other methods). MA: Sinauer Associates, Sunderland.

Telles MP, Bastos RP, Soares TN, Resende LV, et al. (2006). RAPD variation and population genetic structure of Physalaemus cuvieri (Anura: Leptodactylidae) in Central Brazil. Genetica 128: 323-332.

Viegas-Péquignot E (1992). In situ hybridization to chromosomes with biotinilated probes. In: In situ hybridization: a practical approach (Willernson D, ed.). Oxford University Press and IRL Press, Oxford, 137-158.

Williams JG, Kubelik AR, Livak KJ, Rafalski JA, et al. (1990). DNA polymorphisms amplified by arbitrary primers are useful as genetic markers. Nucleic Acids Res. 18: 6531-6535.

Williams SE and Hero JM (1998). Rainforest frogs of the Australian Wet Tropics: guild classification and the ecological similarity of declining species. Proc. Biol. Sci. 265: 597-602.

Wynn A and Heyer WR (2001). Do geographically widespread species of tropical amphibians exist? An estimate of genetic relatedness within the Neotropical frog Leptodactylus fuscus (Schneider 1799) (Anura Leptodactylidae). Trop. Zool. 14: 255-285.

Yeh FC, Yang R and Boyle T (1999). POPGENE version 1.32: Microsoft Window-based freeware for population genetics analysis. University of Alberta, Edmonton. Free program distribuited by the authors at http://www.ualberta.ca/fyeh/ index.htm.

Zeisset I and Beebee TJ (2003). Population genetics of a successful invader: the marsh frog Rana ridibunda in Britain. Mol. Ecol. 12: 639-646. 